\title{
A Fracture Mechanics Approach for Evaluating the Effects of Heat Aging on Fatigue Crack Growth of Vulcanized Natural Rubber*
}

\author{
Prabhakar SOMA**, Naoya TADA***, Makoto UCHIDA***, \\ Kazunari NAKAHARA** and Yoshifumi TAGA** \\ ** Kurashiki Kako Co. Ltd. \\ 4630, Yagara, Tsurajima-cho, Kurashiki, Okayama, Japan 712-8555 \\ E-mail:soma-p@kuraka.co.jp \\ *** Graduate School of Natural Science \& Technology, Okayama University \\ 3-1-1 Tsushima-naka, Kita-ku, Okayama, Japan 700-8530
}

\begin{abstract}
Influence of heat aging on fatigue crack growth properties of vulcanized natural rubber used in engine mount applications were studied based on fracture mechanics approach. Heat aging of the pure shear specimens was carried out at $70^{\circ} \mathrm{C}$ and $100^{\circ} \mathrm{C}$ for a period ranging from $24 \mathrm{~h}$ to $168 \mathrm{~h}$. The tearing energy at various tensile strains was calculated from the stress-strain curves obtained from the static tests of the specimens. Fatigue crack growth rate was calculated from the cyclic tests of the specimens at constant displacement conditions and results were presented as a function of tearing energy. The crack growth rate at a given tearing energy was higher for specimens aged at $100^{\circ} \mathrm{C}$ and increased with the increase in aging period. The crack growth rate was not much affected for the specimens aged at $70^{\circ} \mathrm{C}$. Also, the effect of heat aging on molecular mobility was studied by measuring spin-spin relaxation time $T_{2}$ using pulsed Nuclear Magnetic Resonance (NMR).
\end{abstract}

Key words: Natural Rubber, Fatigue Crack Growth, Tearing Energy, Heat Aging, Displacement Controlled Test, Spin-spin Relaxation Time

\section{Introduction}

Engine mounts are rubber-to-metal bonded elements and are important component of powertrain system in automotive applications. The excellent characteristics of rubber materials such as ability to withstand large elastic deformation, excellent damping and energy absorption characteristics have made them to be used in many applications like engine mounts, tires and suspension bushes etc. Since these applications impose large static and time-varying strains, fatigue analysis and strength evaluation are very important in product development process ${ }^{(1)}$. Engine mounts experience repeated loads during operation and fatigue failure may occur after a certain period of life. Fracture of rubber is initiated from imperfections present in the body and form cracks and they bring about the final fracture under applied loads. Thus the crack growth properties of rubber are important in deciding its strength ${ }^{(2)}$.

Many researchers have studied the fatigue crack growth rate of elastomers and the effect of various factors like frequency, temperature, fillers and ozone ${ }^{(3)-(8)}$. In typical automotive applications, for example engine mounts, the effect of temperature on fatigue

${ }^{\star}$ Received 16 Nov., 2009 (No. e117) [DOI: 10.1299/jmmp.4.727]

Copyright $\odot 2010$ by JSME 
life is very important as the mount experiences heat generated from the engine and also heat generated from hysteresis loss. The rubber mounts become aged after prolonged exposure to heat resulting in deterioration of mechanical properties and hence, fatigue life because of thermo-oxidative degradation (main chain scission and or crosslink scission) of rubber during heat aging ${ }^{(9)-(14)}$. Fatigue crack growth properties at various heat aging conditions were also studied previously ${ }^{(15)(16)}$, but the study results were not enough to simulate the operating conditions experienced by engine mounts in automotive applications. Understanding the effect of heat aging on fatigue crack growth behavior in a range of tearing energies is of utmost importance to determine the total service lifetime of rubber components.

This research will be primarily concerned with the effect of heat aging on mechanical properties and fatigue crack growth rate of vulcanized natural rubber used in engine mount applications. The effect of heat aging on molecular mobility, which is related to the crosslink structure, was also studied by measuring spin-spin relaxation time $T_{2}$ using pulsed Nuclear Magnetic Resonance (NMR).

\section{Experiment}

\subsection{Preparation of pure shear specimens and testing equipment:}

The specimen used in this work was "pure shear" ${ }^{(17)}$ specimen and is shown in Fig.1. The advantage of pure shear specimen is that the tearing energy is constant and crack grows uniformly during the test under fixed displacement conditions. The specimens were prepared by vulcanizing the rubber between two metal plates to avoid the difficulties in clamping the rubber sheets during testing process. The material used for this study was carbon-filled vulcanized natural rubber with a hardness of 55 shore A. The thickness, length and height of the rubber part were designed to be 2, 200 and $20 \mathrm{~mm}$ respectively to maintain the condition of "pure shear" in the central region of the specimen. To study the effect of heat aging, rubber specimens were heat-aged in air circulated oven. The aging temperatures for this study were selected as $70^{\circ} \mathrm{C}$ and $100^{\circ} \mathrm{C}$ and aging periods as $24 \mathrm{~h}, 72 \mathrm{~h}, 120 \mathrm{~h}$ and 168h. These heat aging conditions were selected so as to mimic accelerated aging tests in automotive applications. The temperature in the oven was set to required temperatures and the specimens were placed in the oven after the temperature in oven raised to set temperature.

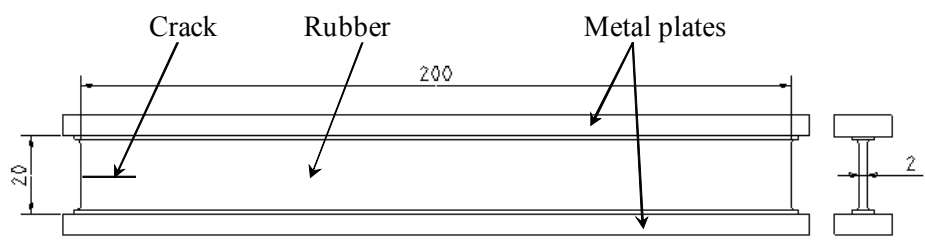

Fig.1 Pure shear test specimen (mm).

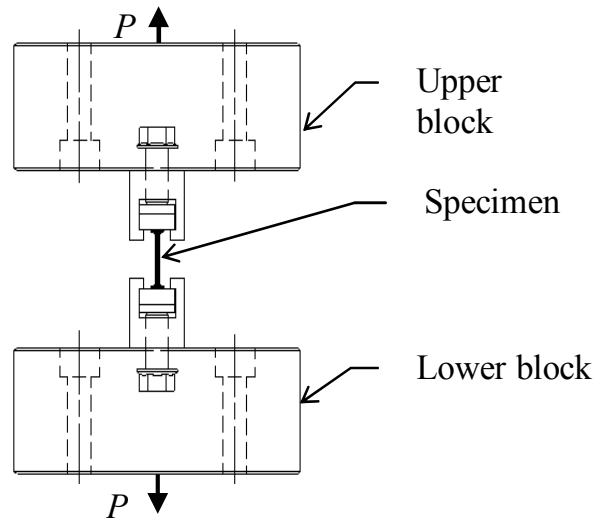

Fig.2 Test jig. 


\subsection{Fatigue crack growth measurements:}

The fatigue tests of pure shear specimens of both aged and un-aged were conducted using a single axis fatigue-testing machine. A jig was prepared to clamp the metal plates of specimen firmly. The hydraulic actuator of the testing machine was connected to the lower block of jig whereas the load cell was connected to the upper block. A crack, with a length of about $30 \mathrm{~mm}$ was made on one end of the specimen using a sharp razor blade. Fatigue tests were conducted at room temperature under displacement-controlled conditions at a testing frequency of $3 \mathrm{~Hz}$. The applied tensile strain varied from $25 \%$ to $65 \%$ and all the

(a)

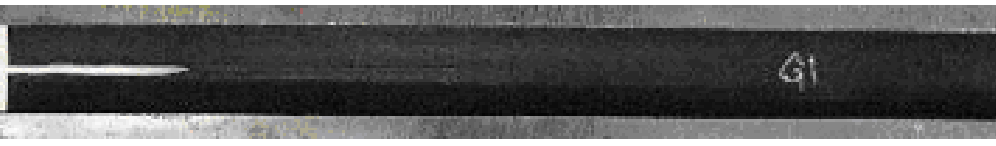

(b)

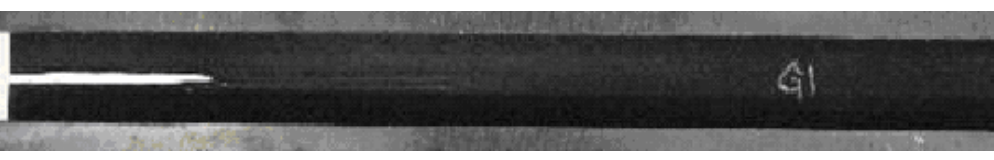

(c)

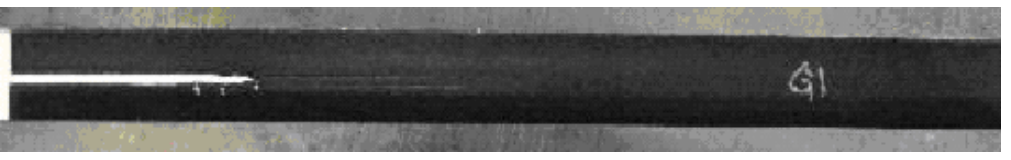

Fig.3 Crack growth observations in specimen.
(a) $N=0$
(b) $N=10000$
(c) $N=24500$

experiments were conducted under fully relaxing conditions, i.e. the specimen is allowed to return to unstrained condition at the end of each cycle. The tensile strain can be defined as the ratio of input displacement to original height of the specimen. The machine was stopped periodically to measure and note the crack length and number of loading cycles. The crack length was measured at unstrained condition using a digital slide caliper. Crack growth photographs of an unaged specimen captured during a fatigue test are shown in Fig. 3.

\subsection{Tearing energy calculations:}

Rivlin and Thomas ${ }^{(17)}$ showed that the fracture of rubber is controlled by strain energy release rate, or tearing energy and is given by,

$$
T=-\left(\frac{\partial W}{\partial A_{c}}\right)_{L}
$$

where, $T$ is tearing energy, $W$ is total elastic energy stored in specimen and $A_{c}$ is the area of one fracture surface of the crack. The partial derivative indicates that the sample is considered at a fixed displacement $L$ and no external work applied. They also showed that the tearing energy for pure shear geometry is independent of crack length and is given by,

$$
T=U h
$$

where, $U$ is strain energy density and $h$ is unstrained height of specimen. The strain energy density in this research was calculated from the collected stress-strain data of the uncut specimen at different levels of strain of interest.

For a given strain level, the strain energy density, $U$ was increased for aged specimens as the rubber gets hardened because of the aging process. The hardness and stiffness increases as the aging temperature and/or aging period increase. The stress-strain curves obtained from a tensile test for the specimens aged at $70^{\circ} \mathrm{C}$ and $100^{\circ} \mathrm{C}$ are shown in Fig.4.

\subsection{Measurement of mechanical properties using dumbbell specimens:}

The deterioration of mechanical properties due to heat aging was measured using dumbbell test specimens. Vulcanized rubber sheets of $2 \mathrm{~mm}$ thick were prepared by injection 
molding and dumbbell test specimens of type JIS (Japanese Industrial Standard) No.3 were cut from the sheets along the grain direction after $24 \mathrm{~h}$ of conditioning period. The dimensions of the dumbbell specimens are shown in Fig.5. Aging of the specimens was done in a hot air oven at $70^{\circ} \mathrm{C}$ and $100^{\circ} \mathrm{C}$. The specimens were withdrawn from the oven after specific periods. After a conditioning period of $24 \mathrm{~h}$, the tensile tests were conducted according to JIS $\mathrm{K} 6251$, at a stretching rate of $500 \mathrm{~mm} / \mathrm{min}$. The mechanical properties such as tensile breaking strength, elongation at break, $100 \%$ modulus and $300 \%$ modulus were measured to study the

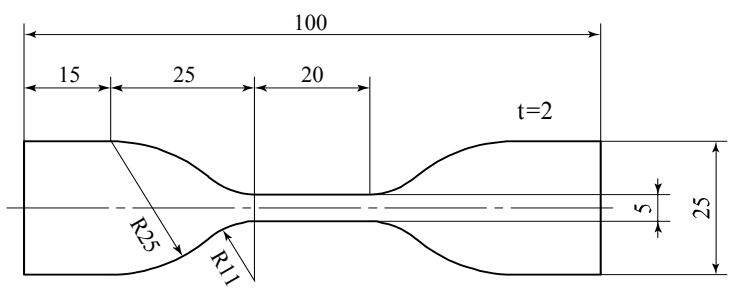

Fig.5 Dumbbell specimen used in tensile tests ( $\mathrm{mm})$. effect of heat aging.

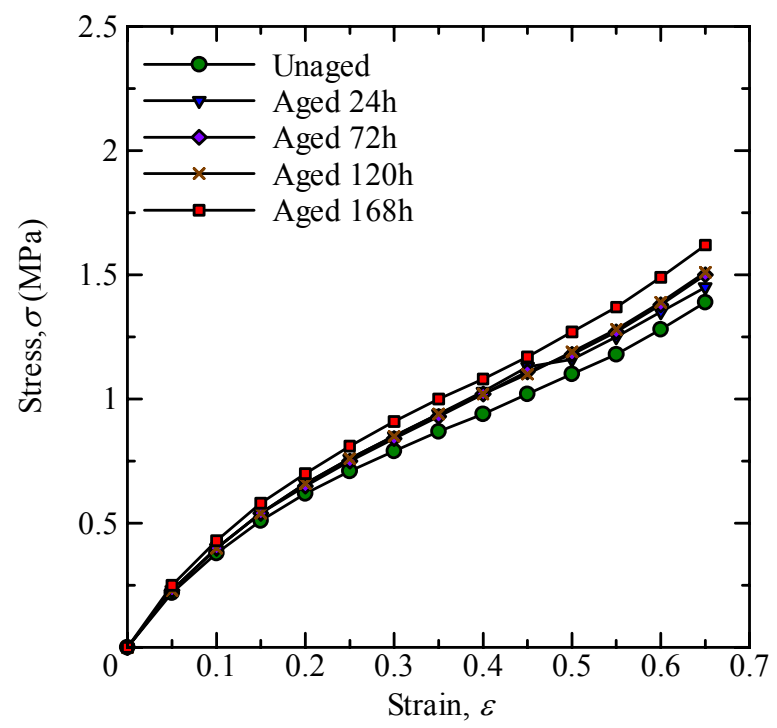

(a) At aging temperature $70^{\circ} \mathrm{C}$.

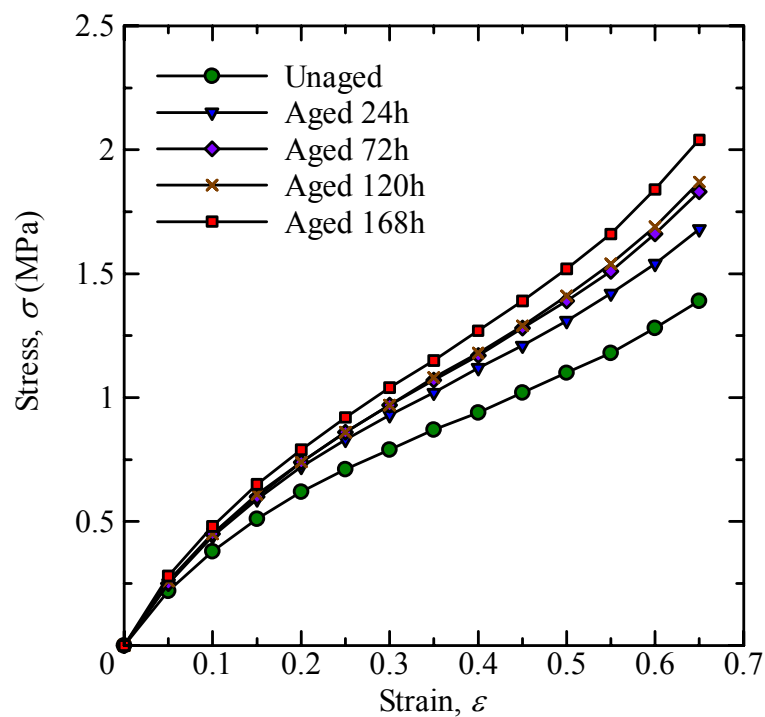

(b) At aging temperature $100^{\circ} \mathrm{C}$.

Fig.4 Stress-strain curves of pure shear specimens at various aging conditions. 


\subsection{Spin-spin relaxation time measurements using NMR:}

The effect of heat aging on molecular mobility of rubber was investigated by measuring the spin-spin relaxation time $T_{2}$ by pulsed nuclear magnetic resonance (NMR). The apparatus, JEOL JNM-MU25 spectrometer operating at a $1 \mathrm{H}$ resonant frequency of $25 \mathrm{MHz}$ was used to measure the $T_{2}$. The aged and unaged specimens were cut into small pieces, approximately $2 \mathrm{~mm}$ in size and placed in testing tube of the apparatus. The $T_{2}$ was measured from free induction decay (FID) followed by a $90^{\circ}$ single pulse. The FID curve, $M(t)$, is fitted to the Weibull function ${ }^{(18)(19)}$ as follows,

$$
M(t)=M_{0} \exp \left\{-\left(\frac{t}{T_{2}}\right)^{W}\right\}
$$

where, $W$ is Weibull coefficient, $M_{0}$ is signal intensity at $t=0$ and $T_{2}$ is spin-spin relaxation time.

\section{Results and Discussion}

\subsection{Effect of heat aging on mechanical properties:}

The change in tensile strength $\sigma_{\mathrm{T}}$, elongation at break $\varepsilon_{\mathrm{B}}, 300 \%$ modulus $E_{300}$ and $100 \%$ modulus $E_{100}$ with respect to aging period are shown in Figs.6-9 respectively. It can be observed from the results that both the tensile strength and elongation at break were decreased with the increase in aging period. But the $100 \%$ modulus and $300 \%$ modulus were slightly increased with the increase in aging period as the rubber gets hardened because of the aging process. The variation in hardness due to heat aging at different aging conditions is shown in Fig.10. The deterioration of mechanical properties was more prominent for specimens aged at $100^{\circ} \mathrm{C}$ than at $70^{\circ} \mathrm{C}$. The drop in tensile strength was about $4 \%$ for the specimen aged at $70^{\circ} \mathrm{C}$ for $168 \mathrm{~h}$ whereas it was about $20 \%$ for the specimen aged at $100^{\circ} \mathrm{C}$ for $168 \mathrm{~h}$. Similarly the drop in elongation at break was about $8 \%$ for the specimen aged at $70^{\circ} \mathrm{C}$ for $168 \mathrm{~h}$ whereas it was about $25 \%$ for the specimen aged at $100^{\circ} \mathrm{C}$ for $168 \mathrm{~h}$. The fall in elongation at break at initial stages of aging was much sharper for the specimens aged at $100^{\circ} \mathrm{C}$. The $100 \%$ modulus and $300 \%$ modulus were increased steadily with aging period for $70^{\circ} \mathrm{C}$ aged specimens. However for $100^{\circ} \mathrm{C}$ aged specimens, they were increased up to a period of $120 \mathrm{~h}$ and then the change was not significant between $120 \mathrm{~h}$ and $168 \mathrm{~h}$.

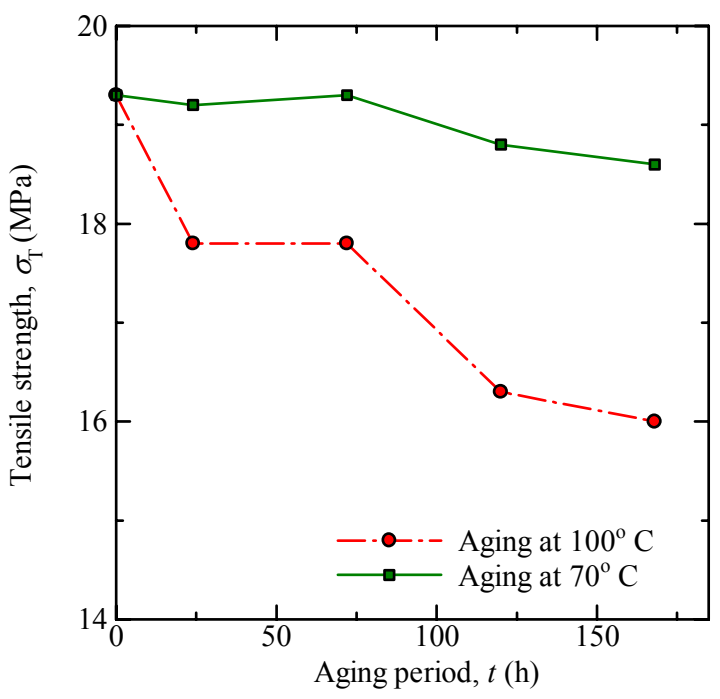

Fig.6 Variation in tensile strength after aging. 


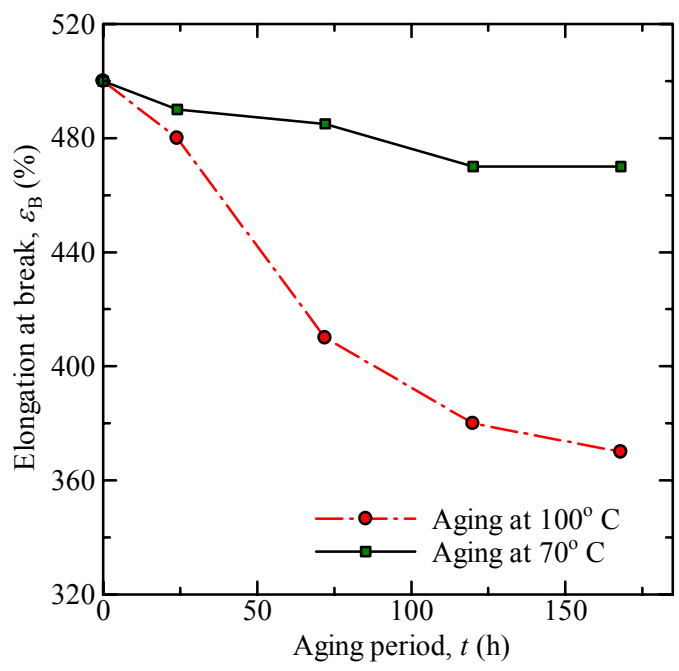

Fig.7 Variation in elongation at break after aging.

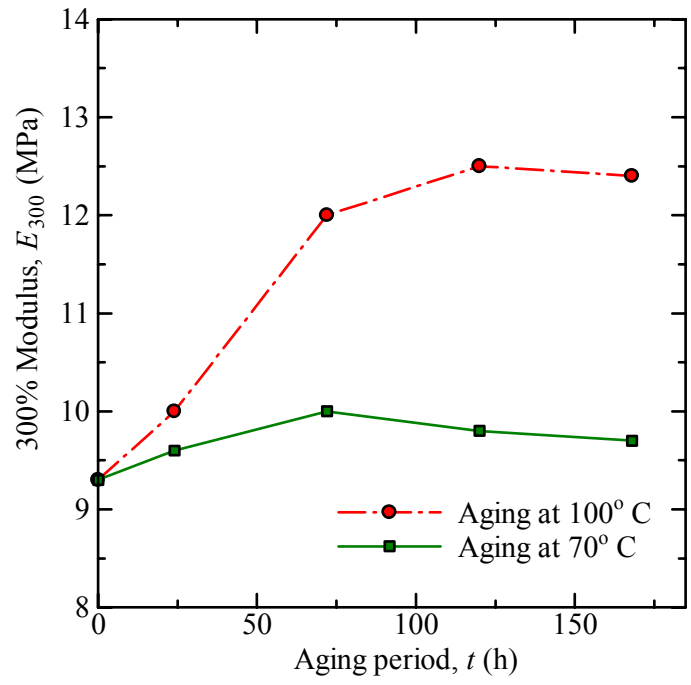

Fig.8 Variation in 300\% modulus after aging.

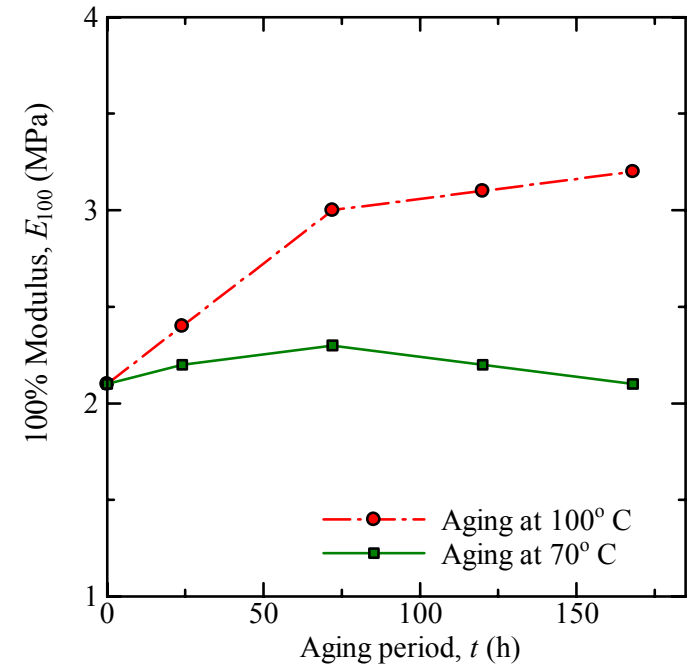

Fig.9 Variation in 100\% modulus after aging. 


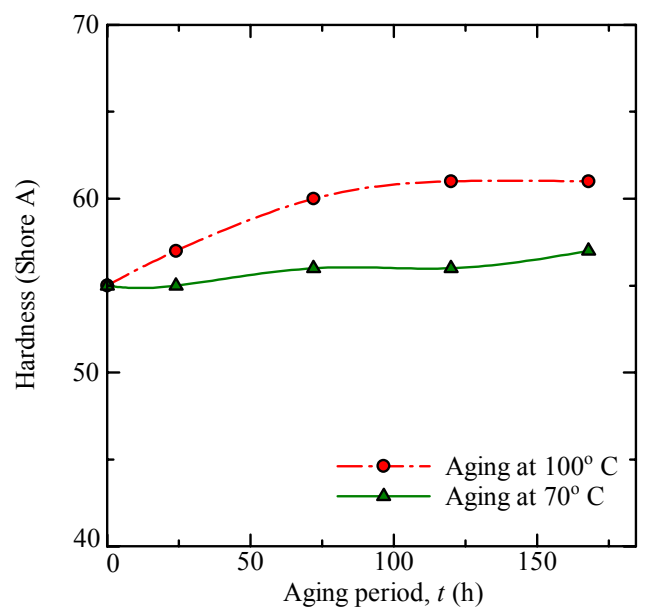

Fig.10 Variation of hardness after aging.

\subsection{Effect of heat aging on fatigue crack growth:}

Tearing energies at different strain levels were calculated from stress-strain curves of pure shear specimens and plotted against aging period in Fig.11. The tearing energy was increased with the increase in aging period as the modulus increased because of heat aging process. At $65 \%$ strain, aging period of $168 \mathrm{~h}$, the increase in tearing energy was about $12 \%$ for the specimens aged at $70^{\circ} \mathrm{C}$ and $35 \%$ for the specimens aged at $100^{\circ} \mathrm{C}$. Tearing energy was almost constant between the aging periods $72 \mathrm{~h}$ and $120 \mathrm{~h}$ at both the aging temperatures. The increase in tearing energy was more noticeable for the specimens aged at $100^{\circ} \mathrm{C}$ than at $70^{\circ} \mathrm{C}$.

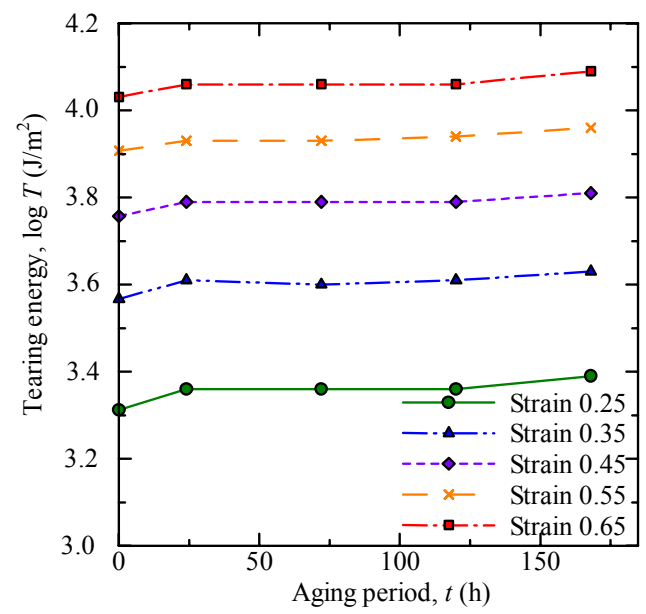

(a) At aging temperature $70^{\circ} \mathrm{C}$.

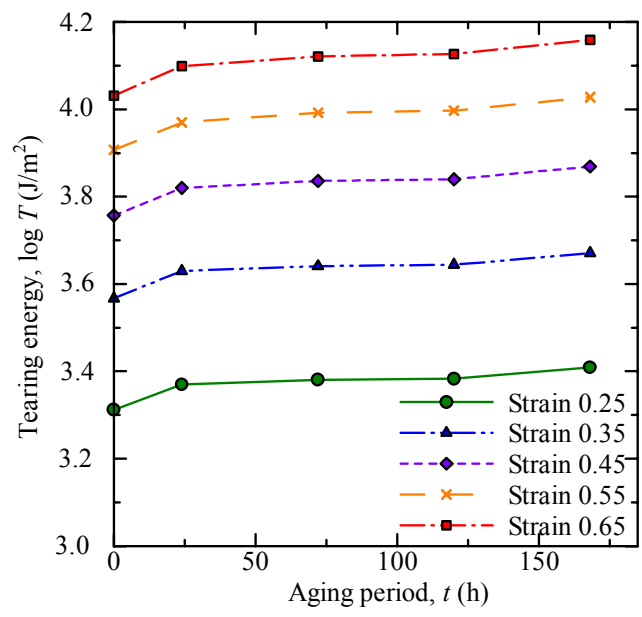

(b) At aging temperature $100^{\circ} \mathrm{C}$.

Fig.11 Tearing energy versus aging period. 


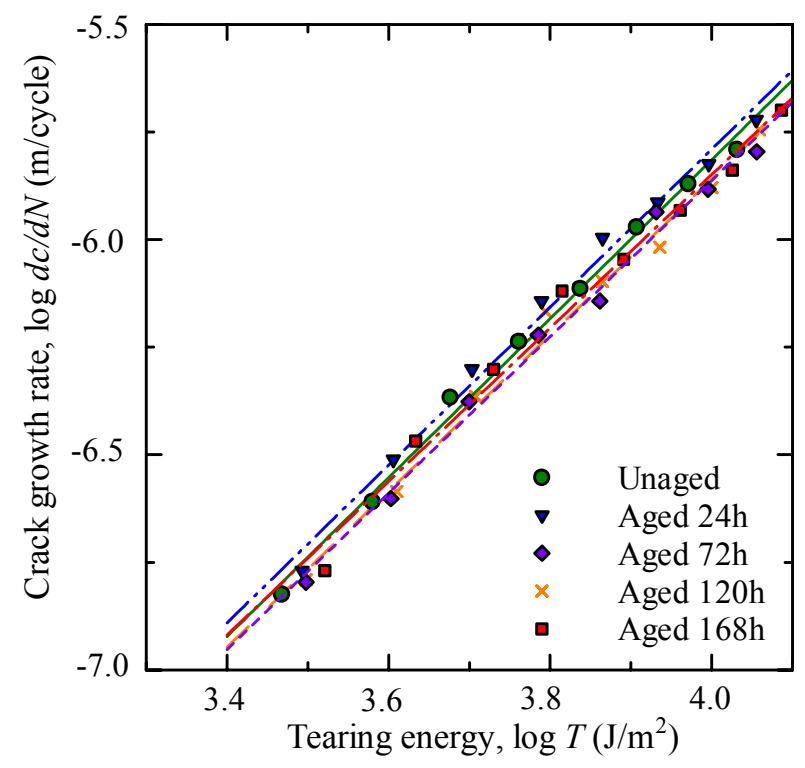

Fig. 12 Crack growth rate versus tearing energy at aging temperature $70^{\circ} \mathrm{C}$.

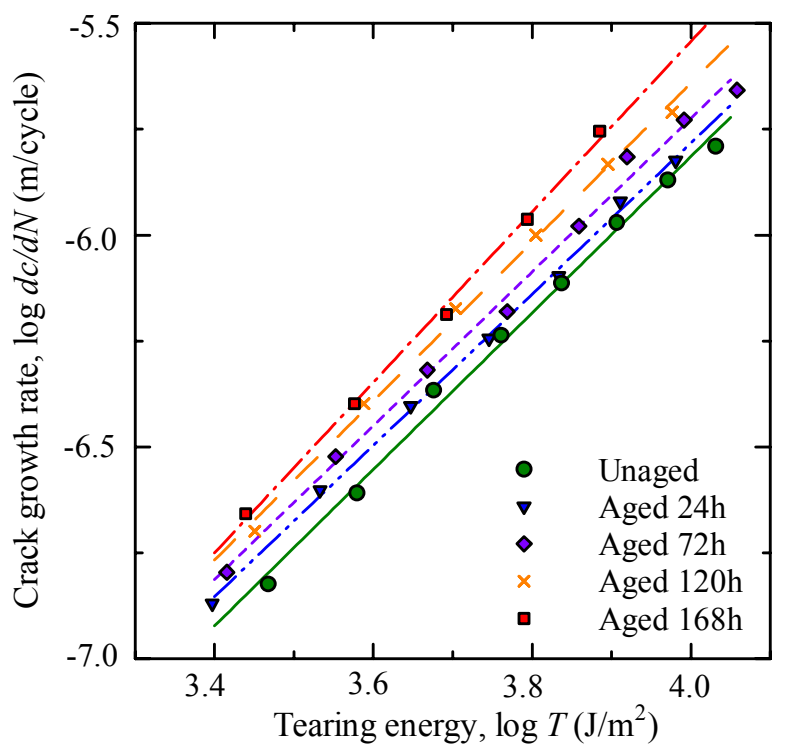

Fig. 13 Crack growth rate versus tearing energy at aging temperature $100^{\circ} \mathrm{C}$.

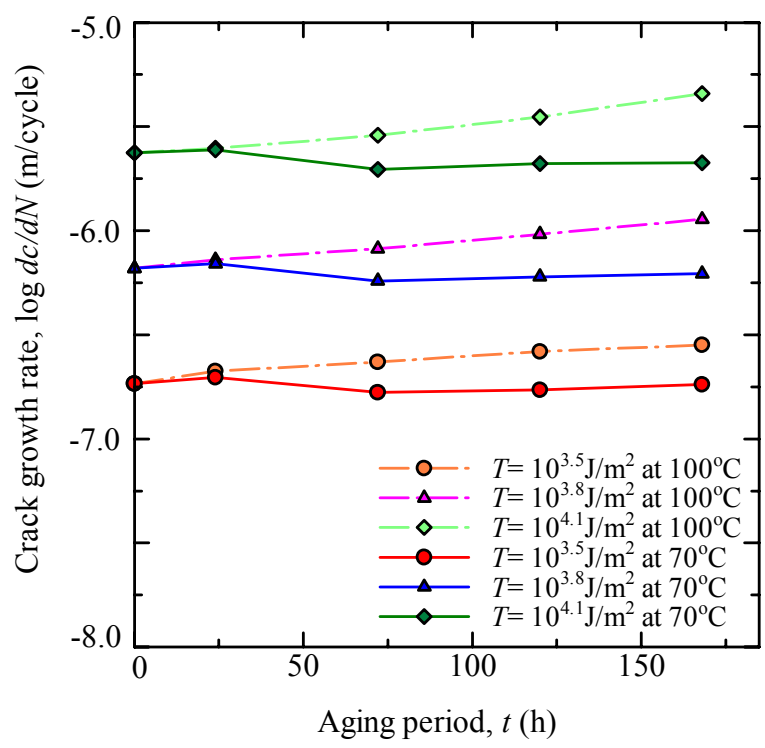

Fig.14 Crack growth rate versus aging period at different tearing energies. 
The crack growth rate versus tearing energy plots for the specimens aged at $70^{\circ} \mathrm{C}$ and $100^{\circ} \mathrm{C}$ are shown in Figs. 12 and 13 respectively. It can be observed that the fatigue crack growth rate increased with tearing energy over a range of tearing energies employed in this work $\left(10^{3.4} \mathrm{~J} / \mathrm{m}^{2}\right.$ to $\left.10^{4.1} \mathrm{~J} / \mathrm{m}^{2}\right)$, obeying power law. The slope of the fatigue crack growth rate curves was ranged from 1.77 to 2.01 . These values are similar to the results from other studies ${ }^{(3)(4)(16)}$. The crack growth rates at specific tearing energies versus aging period results are shown in Fig.14. For the specimens aged at $100^{\circ} \mathrm{C}$, the crack growth rate at a given tearing energy was higher than unaged specimens and increased with the increase in aging period. At a tearing energy of $6300 \mathrm{~J} / \mathrm{m}^{2}\left(10^{3.8} \mathrm{~J} / \mathrm{m}^{2}\right)$, the fatigue crack growth rate was increased by about 1.72 times after aging the specimens for $168 \mathrm{~h}$ at $100^{\circ} \mathrm{C}$ whereas the fatigue crack growth rate was almost constant for all the specimens aged at $70^{\circ} \mathrm{C}$. This is in agreement with the changes in mechanical properties observed from dumbbell specimen test results discussed above and spin-spin relaxation time results obtained from NMR tests that will be discussed in next section.

\subsection{Effect of heat aging on molecular mobility:}

The crosslink density and crosslink structures (polysulfidic, disulfidic and monosulfidic crosslinks) are considered to be changed by the heat aging process ${ }^{(10)-(13)}$. Since the total crosslink density is proportional to the modulus at a certain extension ratio ${ }^{(20)}$, the increase in modulus of specimens shown in Figs. 8 and 9 confirms the increase in crosslink density due to heat aging. The ratio of relatively rigid crosslinks such as disulfidic or monosulfidic cross-links are expected to be increased because of crosslink scission during heat aging. This can be seen from the decrease in elongation at break $\left(\varepsilon_{\mathrm{B}}\right)$ results shown in Fig.7. Since disulfidic and monosulphidic crosslinks are not flexible and cannot relieve cyclic stresses as efficiently as polysulfidic crosslinks, it is considered that the crack growth rate of aged specimens was higher than unaged specimens at a given tearing energy. The change in ratio of disulfidic or monosulfidic crosslinks is related to the mobility of molecules and was measured from NMR experiments. The results of spin-spin relaxation time against heat aging period are plotted in Fig. 15.

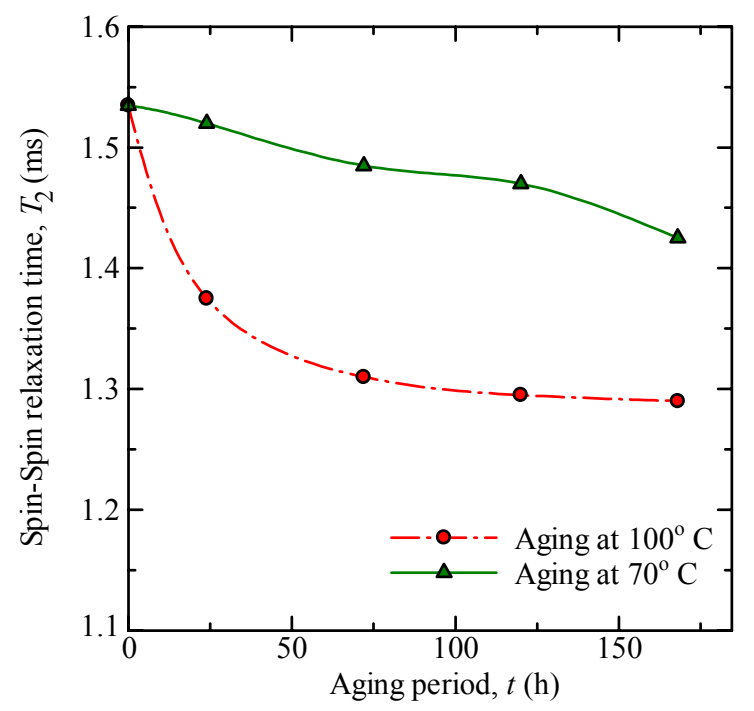

Fig.15 Variation in spin-spin relaxation time after aging.

The measurements show significant difference between aged and unaged samples. A drastic fall in $T_{2}$ was observed for the specimens aged at $100^{\circ} \mathrm{C}$ showing reduction in free mobility of chain segments. However the fall was much less sharp between aging periods of 
$72 \mathrm{~h}$ and $168 \mathrm{~h}$. The trend of fall in $T_{2}$ was very much similar to the one reported in earlier study ${ }^{(21)}$. A corresponding increase in crack growth rate was observed in tearing energy versus crack growth rate plots shown in Fig.13. On the other hand, the effect of aging at $70^{\circ} \mathrm{C}$ on material structure was found to be very less as the fall in $T_{2}$ was marginal. A similar trend in crack growth rates were observed in crack growth rate versus tearing energy plots shown in Fig. 12.

\section{Conclusion}

The effect of heat aging on fatigue crack growth rate of vulcanized natural rubber was studied using fracture mechanics approach. Fatigue tests were conducted at different tensile strains and the results were presented as power law relations between the crack growth rate $d c / d N$ and tearing energy $T$. The crack growth rate at a given tearing energy was higher for the specimens aged at $100^{\circ} \mathrm{C}$ and increased with the increase in aging period. However, the crack growth rate was not much affected for the specimens aged at $70^{\circ} \mathrm{C}$. The effect of heat aging on change of molecular mobility was also investigated by measuring the spin-spin relaxation time $T_{2}$ by pulsed NMR. The measurements show significant difference between aged and unaged samples reflecting the change in crosslink density and molecular structure by heat aging process. The results of deterioration in mechanical properties, reduction in spin-spin relaxation time and the increase in fatigue crack growth rate due to heat aging are correlated with each other.

\section{References}

(1) Mars, W.V. and Fatemi, A., A literature survey on fatigue analysis approaches for rubber, International Journal of Fatigue, 24, 949-961 (2002).

(2) Lake, G.J and Thomas, A.G., Strength. In: Gent, A., editor. "Engineering with rubber, How to design rubber components", Munich: Carl Hanser Verlag, chapter 5 (1992).

(3) Young, D.G., Fatigue crack propagation in elastomer compounds: Effects of strain rate, temperature, strain level, and oxidation, Rubber Chemistry and Technology, 59, 809-825 (1986).

(4) Lake, G.J and Lindley, P.B., Mechanical fatigue limit for rubber, Rubber Chemistry and Technology, 39, 348-364 (1966).

(5) Royo, J., Fatigue testing of rubber materials and articles, Polymer Testing, 11, 325-344 (1992).

(6) Legorju-jago, K and Bathias, C., Fatigue initiation and propagation in natural and synthetic rubbers, International Journal of Fatigue, 24, 85-92 (2002).

(7) Saintier, N., Cailletaud, G., Piques, R., Crack initiation and propagation under multiaxial fatigue in a natural rubber, International Journal of Fatigue, 28, 61-72 (2006).

(8) Lindley, P.B. and Teo, S.C., Energy for crack growth at the bonds of rubber springs, Plastics and Rubber Material and Applications, 4, 29-37 (1979).

(9) Yanyo, L.C., Effect of crosslink type on the fracture of natural rubber vulcanizates, International Journal of Fracture, 39, 103-110 (1989).

(10) Blackman, E.J. and McCall, E.B., Relationships between the structures of natural rubber vulcanizates and their thermal and oxidative aging, Rubber Chemistry and Technology, 43, 651-663 (1970). 
(11) Colclough, T., Cunneen, J.I., Higgins, G.M.C., Oxidative aging of natural rubber vulcanizates. Part III. Crosslink scission in monosulfidic networks, J.Appl.Polym.Sci., 12, 295-307 (1968).

(12) Hamed, G.R. and Zhao, J., Tensile behavior after oxidative aging of gum and black-filled vulcanizates of SBR and NR, Rubber Chemistry and Technology, 72, 721-730 (1999).

(13) Woo, C.S. and Kim, W.D., Heat-aging effects on the material properties and fatigue life prediction of vulcanized natural rubber, e-Journal of Soft Materials, 2, 7-12 (2006).

(14) Hamed, G.R. and Rattanasom, N., Effects of crosslink density on cut growth in black-filled natural rubber vulcanizates, Rubber Chemistry and Technology, 75, 935-941 (2002).

(15) Mathew, N.M. and De, S.K., Thermo-oxidative ageing and its effect on the network structure and fracture mode of natural rubber vulcanizates, Polymer, 24, 1042-1054 (1983).

(16) Kim, S.G. and Lee, S.H., Effect of crosslink structures on the fatigue crack growth behaviour of NR vulcanizates with various aging conditions, Rubber Chemistry and Technology, 67, 649-661 (1994) .

(17) Rivlin, R.S. and Thomas, A.G., Rupture of Rubber. I. Characteristic energy for tearing, J.Polym.Sci., 10, 291-318 (1953).

(18) Serizawa, H., Ito, M., Kanamoto, T., Tanaka, K., Nomura, A., Structural changes during mechanical mixing in carbon black-natural rubber systems studied by pulsed NMR, Polymer J., 14, 149-154 (1982).

(19) Kaufman, S., Slichter, W.P., Davis, D.D., Nuclear magnetic resonance study of rubber-carbon black interactions, J.Polym.Sci., Part A-2, 9, 829-839 (1984).

(20) Asahiro, A., Extensibility of black-filled elastomers, Rubber Chemistry and Technology, 59, 187-203 (1986).

(21) Somers, A.E., Bastow, T.J., Burgar, M.I., Forsyth, M., Hill, A.J., Quantifying rubber degradation using NMR, Polymer Degradation and Stability, 70, 31-37 (2000). 